\title{
Lithium Iron Phosphate: Olivine Material for High Power Li-Ion Batteries
}

\author{
Christian M Julien $^{1 *}$, Xiaoyu Zhang ${ }^{2}$ and Alain Mauger ${ }^{1}$ \\ ${ }^{1}$ Department of Materials and Cosmology, France \\ ${ }^{2}$ SynPLi Consulting, CIAPS, France
}

*Corresponding author: Christian M Julien, Department of Materials and Cosmology, UPMC Univ. Paris 6, UMR 7590, 4 Place Jussieu, 75005 Paris, France

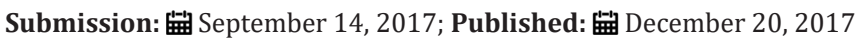

\section{Introduction}

Lithium iron phosphate $\mathrm{LiFePO}_{4}$ (LFP) has been selected as one of the positive electrode material of batteries for electric vehicles (EVs) and hybrid electric vehicles (HEVs), and more generally for high-power applications, owing to its thermal and structural stability in the fully charged state, its little hygroscopicity and its exceptional high-rate performance [1]. This material exhibits a relatively large specific capacity even at high C-rate (close to the theoretical value of $170 \mathrm{mAhg}^{-1}$ ) compared with other iron-based compounds. This is because LFP has a well-developed crystalline lattice (olivine-like, orthorhombic structure, Pnma space group) with homogeneous particle size $(<500 \mathrm{~nm})$, purity and physical properties that greatly influence the electrochemical performance of this electrode material. The lithium battery cathode should be a mixed conductor for the transport of both electrons and lithium ions. One of the key features of the olivine is its extremely flat charge/discharge profile categorized as typical of two-phase deinsertion/insertion reaction, while the serious problems as its polaronic insulator character and slow kinetics of ion movement can be overcome by particle-size minimization $(<100 \mathrm{~nm})$, surface modification and/or carbothermal formation of a surface conducting phase. Thus, it is obvious that severe quality control is requested for the use of LFP in high-power batteries.

\section{Structural Features of $\mathrm{LiFePO}_{4}$}

Herewith, we discuss the effect of the presence of impurities or defects on the structural and electrochemical behavior of LFP cathodes. Three types of defects are analyzed.

First type: Presence of the $\mathrm{Li}_{3} \mathrm{PO}_{4}, \mathrm{Fe}_{2} \mathrm{O}_{3}$ or $\mathrm{Fe}\left(\mathrm{PO}_{4}\right)$ phases as impurities in LFP particles. Such defects can be easily detected by XRD or FTIR. Figure 1 shows the typical XRD spectra in the region $2 \theta=18-46^{\circ}$, where Bragg lines of parasitic elements are observed. With the presence of these impurities, the electrochemical performance of LFP electrodes is significantly damaged by the $\mathrm{Fe} \cdot \mathrm{Li}$ defects that block the diffusion path of $\mathrm{Li}^{+}$ions along the corresponding $1 \mathrm{D}$ channel, while $\mathrm{Li}_{3} \mathrm{PO}_{4}$ only acts as an inert mass (electrochemically inactive).

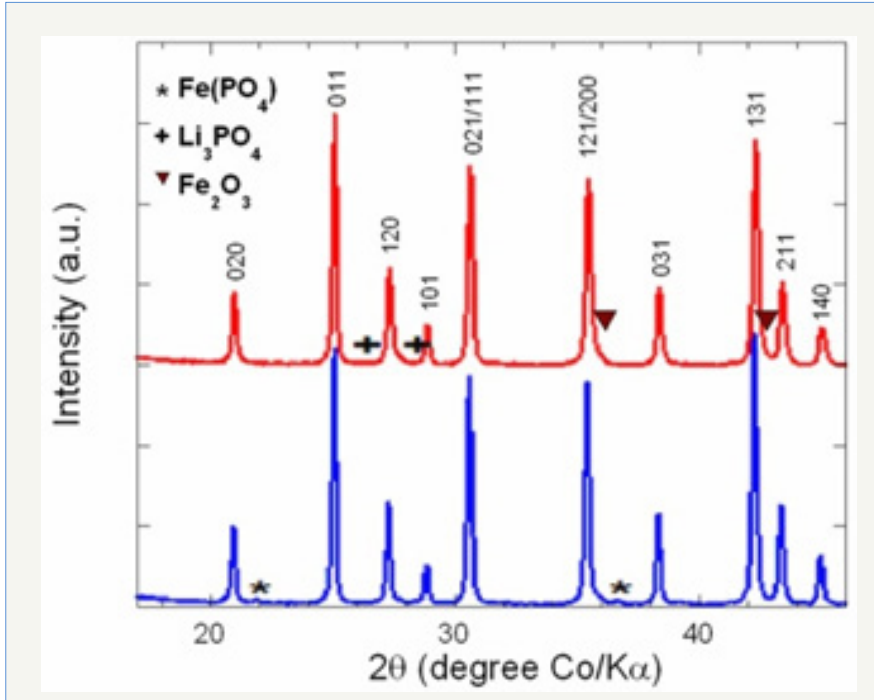

Figure 1: Typical XRD spectra in the region $2 \theta=18-46^{\circ}$

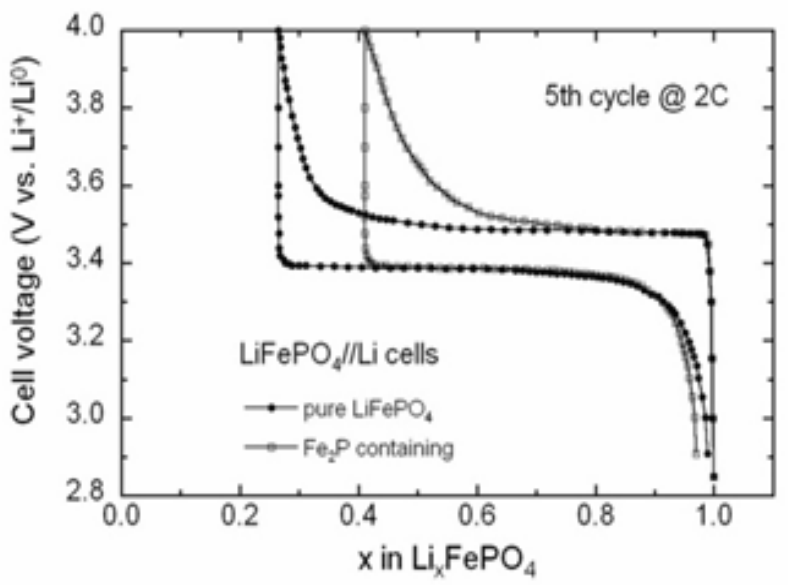

Figure 2: The electrochemical charge-discharge profiles of $\mathrm{Li} /$ /LFP cells cycled at room temperature with pure LFP and with $\mathrm{Fe}_{2} \mathrm{P}$-containing electrode material. 
Second type: presence of the $\mathrm{Fe}_{2} \mathrm{P}$ clusters. Undesirable impurity like $\mathrm{Fe}_{2} \mathrm{P}$ can be introduced during synthesis. It increases the electronic conductivity, but on the other hand it also decreases the ionic conductivity so that both the capacity and cycling rates are degraded with respect to C-LFP composite. The electrochemical charge-discharge profiles of $\mathrm{Li} / / \mathrm{LFP}$ cells cycled at room temperature with pure LFP and with $\mathrm{Fe}_{2} \mathrm{P}$-containing electrode material are shown in Figure 2. It is obvious that at $2 \mathrm{C}$ rate (charge or discharge for $30 \mathrm{~min}$ ), the capacity retention decreases significantly for the material containing few $\%$ of $\mathrm{Fe}_{2} \mathrm{P}$.

Third type: presence of a disordered layer (DSL) on the particle surface. For LFP nano-particles, the fraction (1-y) of iron ions, due to the Li vacancies in the DSL, is not negligible, magnetic measurements have shown that for uncoated particles $\mathrm{Fe}^{3+}$ ions are localized in the low spin state $(S=1 / 2)$. Figure 3 shows the TEM images of the surface of LFP particles before carbon coating (left) and after carbon coating (right). Note that the granular aspect of DSL disappeared after carbon coating. With optimized LFP// LTO electrodes a Li-ion 800-mAh battery has filled a gap in the performance in terms of safety, cycling life, which are key-issues in public transportation [2].

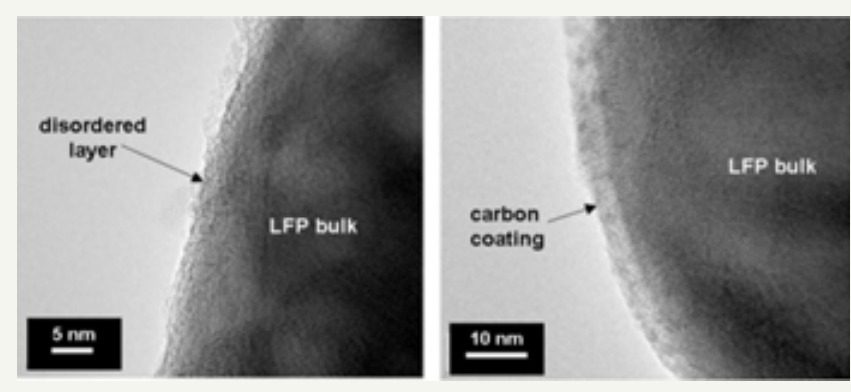

Figure 3: The TEM images of the surface of LFP particles before carbon coating (left) and after carbon coating (right).

\section{Is Doping Possible in $\mathrm{LiFePO}_{4}$ ?}

Since LFP is a very poor electronic conductor, however, some treatment must be performed to make the $\mathrm{LiFePO}_{4}$ powder conductive. Two different strategies were tried. One was to dope the material to make it conductive, by substitute $\mathrm{Fe}^{2+}$ ions for other transition-metal elements in a different valence state. Such attempts led to increase the conductivity by orders of magnitude [3], fostering the idea that it was possible [4]. However, it has been argued that this increase of conductivity was actually due to the formation of conductive surface films either because of formation of conductive carbon films, or metallic impurities such as $\mathrm{Fe}_{2} \mathrm{P}$, or simply precipitation of the metal dopant that cannot enter into the matrix, which have been observed by TEM experiments [5-7].

Neutron and XRD experiments have shown that the limit of solubility of the dopant such and $\mathrm{Zr}, \mathrm{Nb}, \mathrm{Cr}$ is very small, and that they are located primarily on Li sites, as expected from ab initio calculations [8], so that they reduce the diffusion of Li by obstruction of the channels, which degrades the electrochemical performance as shown in Figure 4. The other strategy, which was the winning one, consists in coating $\mathrm{LiFePO}_{4}$ with a conductive layer, usually carbon, although coating with a conductive polymer is also possible. In that case, the increase of the conductivity of the powder is due to the percolating metallic network that drives the electrons at the surface of any particle to the current collector, and the reduction of the particle size to limit the path of the electrons inside any particle to reach its surface. The very high rate performance achieved in [2] has been obtained by particles $90 \mathrm{~nm}$ thick covered with a $3 \mathrm{~nm}$-thick carbon layer, which can be synthesized today at an industrial scale (Figure 3). The purpose of the present paper is to review how the study of the magnetic properties have given a major contribution to the understanding of the properties of $\mathrm{LiFePO}_{4}$, starting with the electronic conduction process due to small magnetic polarons that preclude the possibility of any efficient doping, the role of the carbon coating and the surface modification that it generates due to the Fe-C affinity, which explains the outstanding performance of this material, and the identification of the impurities like $\mathrm{Fe}_{2} \mathrm{P}$ that dissolve in the electrolyte.

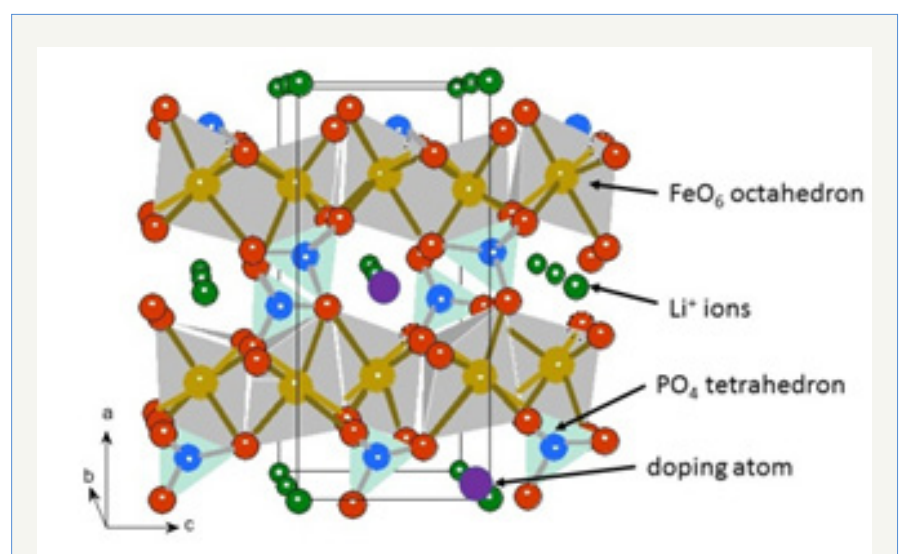

Figure 4: The diffusion of Li by obstruction of the channels, which degrades the electrochemical performance.

\section{Intrinsic Safety of Olivines}

Safety of lithium-ion rechargeable batteries has been the technical obstacle for high power demand applications [9]. Even though the mechanism of thermal runaway is initiated by the anode in combination with the electrolyte [10], the rapid temperature rises in the cell, which dominates the overall heat generated during this process, is produced by the cathode reacting with the electrolyte [11]. Therefore, it is of utmost importance to find a more structurally stable cathode in order to use lithium batteries at their fullest potential.

Here, we discuss the improvement in electrochemical and thermal properties of LFP protected with a thin layer of carbon as a cathode material. 80\% depth-of-discharge (DOD) and the calculated cell resistances $(\Delta \mathrm{V} / \Delta \mathrm{I})$ at different state-of-charge (SOC) indicated that cell resistance remained lower than $34.3 \mathrm{mV}$ to $80 \%$ DOD for both 18s discharge pulses and 10s regenerative charge pulses. Figure 5 presents the self-heat rate (SHR) vs. cell temperature of several 18650-type cells subjected to calorimetric (ARC) test. Comparison of ARC parameters for the different chemistries (anode in graphite) provides the maximum values of SHR: $532,878,6.1$ 
and $158{ }^{\circ} \mathrm{C} / \mathrm{min}$ for $\mathrm{LiNi}_{0.8} \mathrm{Co}_{0.15} \mathrm{Al}_{0.05} \mathrm{O}_{2} / / \mathrm{C}, \mathrm{LiMn}_{2} \mathrm{O}_{4} / / \mathrm{C}, \mathrm{LiFePO}_{4} / / \mathrm{C}$ $(4 \mathrm{~V})$ and $\mathrm{LiFePO}_{4} / / \mathrm{C}(4.2 \mathrm{~V})$, respectively.

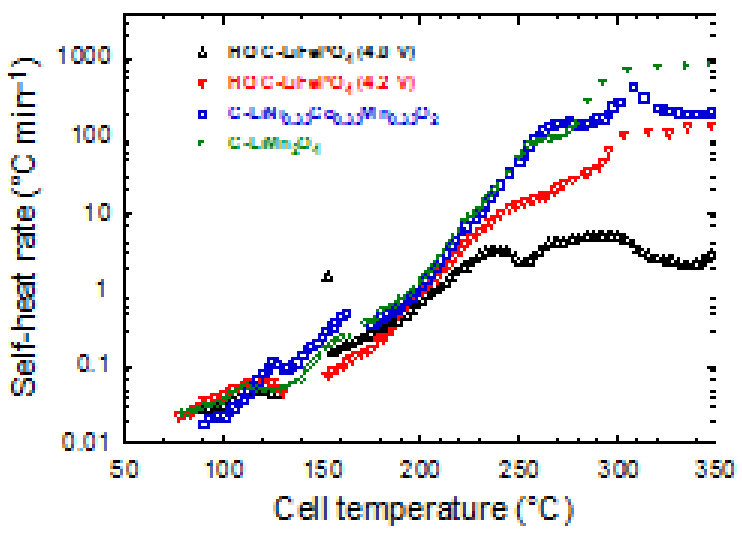

Figure 5: The self-heat rate (SHR) vs. cell temperature of several 18650-type cells subjected to calorimetric (ARC) test.

The C-LFP electrode showed excellent electrochemical performance reaching $152 \mathrm{mAhg}^{-1}$. This electrode also exhibited a reversible capacity corresponding to more than $89 \%$ of the theoretical capacity when cycled between 2.5 and $4.0 \mathrm{~V}$. Cylindrical 18650-type cells with C-LFP cathode material showed only $1.3 \%$ discharge capacity loss for 100 cycles at $0.1 \mathrm{C}$ rate and also delivered $90 \%$ of capacity retention at higher discharge rates up to $5 \mathrm{C}$ rate. The heat generation during charge and discharge at $\mathrm{C} / 2$ rate, studied using IMC, indicated that the cell temperature is not raised above $34^{\circ} \mathrm{C}$ in absence of external cooling. Thermal studies were also investigated by DSC and ARC, which showed that C-LFP is safer, upon thermal and electrochemical abuse, than the commonly used lithium metal oxide cathodes with layered and spinel structures.

\section{Fast Charge of LTO-LFP Li-ion Batteries}

The standard anode of the Li-batteries is carbon based. However, carbon requires formation of a solid/electrolyte interface (SEI) to prevent the formation plating of $\mathrm{Li}$ on the carbon anode during a fast charge of the battery, and the SEI layer is responsible of an irreversible capacity loss. Instead, we used $\mathrm{Li}_{4} \mathrm{Ti}_{5} \mathrm{O}_{12}$ (LTO). This spinel structure has been proposed as a promising candidate as a negative electrode with different positive electrodes, including $\mathrm{LiFePO}_{4}$. The electro-activity occurs at a voltage higher than $1.0 \mathrm{~V}$. Therefore, the electrode does not experience the passivation of the anode materials and their inevitable electrolyte reaction. Also, the lack of strain in this material improves the shelf life, and is another improvement with respect to the carbon that suffers dilatationcontraction upon insertion-extraction of lithium resulting in aging. Figure 6 shows the voltage profiles of Li//LTO and Li//LFP halfcells and the resulting voltage profile of a 18650-type LTO//LFP Li-ion battery charged and discharged at $\mathrm{C} / 24$ rate to approach thermodynamic equilibrium together with the potential-capacity curve of the LTO//LFP lithium-ion battery. The voltage window is $2-4 \mathrm{~V}$ for LFP, $1.2-2.5 \mathrm{~V}$ for LTO. Note that in this figure (and the following one), we have kept the conventional rule, i.e. the capacity is in mAh per gram of the active element of the cathode [12].

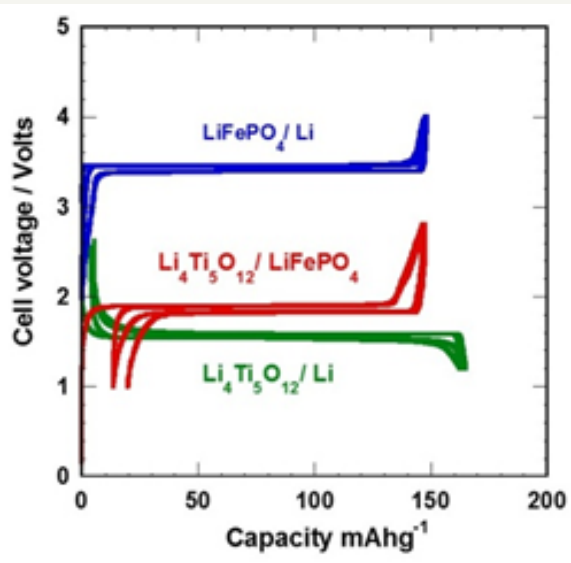

Figure 6: The voltage profiles of $\mathrm{Li} / / \mathrm{LTO}$ and $\mathrm{Li} / / \mathrm{LFP}$ half-cells and the resulting voltage profile of a 18650-type LTO//LFP Li-ion battery charged and discharged at C/24 rate to approach thermodynamic equilibrium together with the potential-capacity curve of the LTO//LFP lithium-ion battery.

We report the performance of an 18650-type Li-ion battery that can be charged within few minutes; it successfully passes the safety tests, and has a very long shelf life. The active materials are nanoparticles of LFP and LTO for the positive and negative electrodes, respectively. LFP particles are covered with $2 \mathrm{wt} . \%$ carbon to optimize the electrical conductivity, but not the LTO particles. The electrolyte is the usual carbonate solvent, i.e. $1 \mathrm{molL}$ ${ }^{1} \mathrm{LiPF}_{6}$ in EC-DEC. The binder is a water-soluble elastomer. LFP was synthesized by the molten-ingot route in a rock of $10 \mathrm{~cm}$ size that was later reduces using roll-crusher and jet-mill process in isopropyl alcohol down to $100 \mathrm{~nm}$. The carbon coating (5wt.\%) was performed using the lactose technique. LTO was prepared by solid-state reaction of precursor materials $\mathrm{TiO}_{2}, \mathrm{Li}_{2} \mathrm{CO}_{3}$ and carbon heated at $850{ }^{\circ} \mathrm{C}$ for $18 \mathrm{~h}$. After milling, LTO nanoparticles were obtained with $150 \mathrm{~nm}$ size.

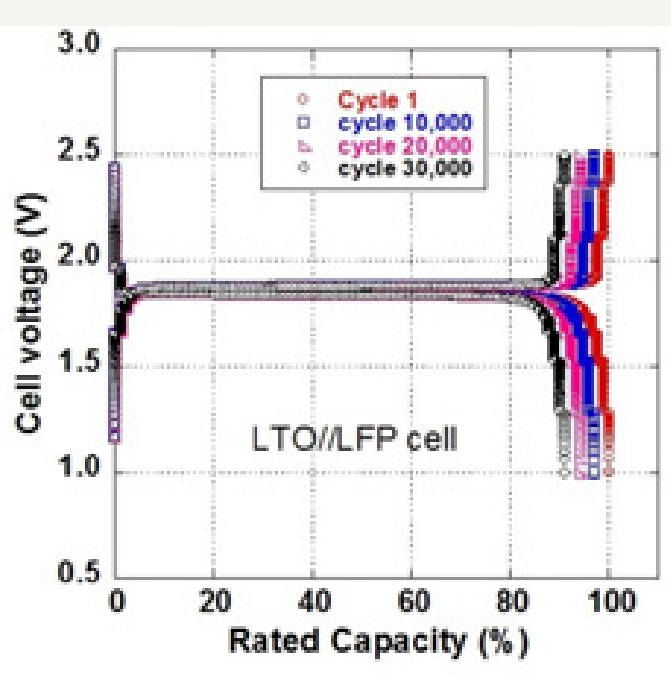

Figure 7: Galvanostatic charge-discharge curves at different cycles, i.e. $1^{\text {st }}, 10,000^{\text {th }}, 20,000^{\text {th }}$ and $30,000^{\text {th }}$ cycle, for discharge at $10 \mathrm{C}$ and charge at $15 \mathrm{C}$ rate. 
Galvanostatic charge-discharge curves at different cycles, i.e. $1 \mathrm{st}, 10,000^{\text {th }}, 20,000^{\text {th }}$ and $30,000^{\text {th }}$ cycle, for discharge at $10 \mathrm{C}$ and charge at $15 \mathrm{C}$ rate are shown in Figure 7 . To complement the electrochemical performance of the LFP//LTO 18650-type batteries, the cycling life is illustrated for charge rate at 10C (6min) and discharge rate 5C (12min). Even after 20,000 cycles, the cell did not lose its initial capacity. The voltage-capacity curves for the LTO//LFP cell during the test are showing very little difference, even at the end of the test.

\section{References}

1. Zaghib K, Dontigny M, Guerfi A, Trottier J, Hamel-Paquet J, et al. (2012) New advanced cathode material: $\mathrm{LiMnPO}_{4}$ encapsulated with $\mathrm{LiFePO}_{4}$. J Power Sources 204: 177-181.

2. Zaghib K, Dontigny M, Guerfi A, Charest P, Mauger A, et al. (2011) Safe and fast-charging Li-ion battery with long shelf life for power applications. J Power Sources 196(8): 3949-3954.

3. Chung SY, Blocking JT, Chang YT (2002) Electronically conductive phospho-olivine as llithium storage electrodes. Nat Mater 1: 123-128.

4. Sun CS, Zhou Z, Xu ZG, Wang DG, Wei JP, et al. (2009) Improved high-rate charge/discharge performan-ces of $\mathrm{LiFePO}_{4} / \mathrm{C}$ via V-doping. J Power Sources 193: 841-845.
5. Ravet N, Abouimerane A, Armand M (2003) Reply to Chung et al. Nat Mater 2: 702.

6. Delacourt C, Wurm C, Laffont L, Leriche JB, Masquelier C (2006) Electrochemical and electrical properties of $\mathrm{Nb}$ - and/or C-containing LiFeP04 composites. Solid State Ionics 177(3-4): 333-341.

7. Herle PS, Ellis B, Coombs N, Nazar LF (2004) Nano-network electronic conduction in iron and nickel olivine phosphates. Nat Mater 3: 147-152.

8. Fisher CA, Prieto MH, Islam MS (2008) Lithium battery materials $\mathrm{LiMPO}_{4}(\mathrm{M}=\mathrm{Mn}, \mathrm{Fe}, \mathrm{Co}, \mathrm{Ni})$ : insights into defect association, transport mechanisms and doping behavior. Chem Mater 20: 5907-5915.

9. Zaghib K, Dubé J, Dallaire A, Galoustov K, Guerfi A, et al. (2012) Enhanced thermal safety and high power performance of carbon-coated $\mathrm{LiFePO}_{4}$ olivine cathode for Li-ion batteries. J Power Sources 219: 36-44.

10. Bang HJ, Yang H, Amine K, Prakash J (2005) Investigations of the exothermic reactions of natural graphite anode for Li-ion batteries during thermal runaway. J Electrochem Soc 152(1): A73-A79.

11. Joachin H, Kaun TD, Zaghib K, Prakash J (2009) Electrochemical and thermal studies of carbon-coated LiFePO4 cathode. J Electrochem Soc 156(6): A401-A406.

12. Zaghib K, Dontigny M, Guerfi A, Trottier J, Hamel-Paquet J, et al. (2012) An improved high-power battery with increased thermal operating range: C-LiFePO $/ /$ C- $\mathrm{Li}_{4} \mathrm{Ti}_{5} \mathrm{O}_{12}$. J Power Sources 216: 192-200. 